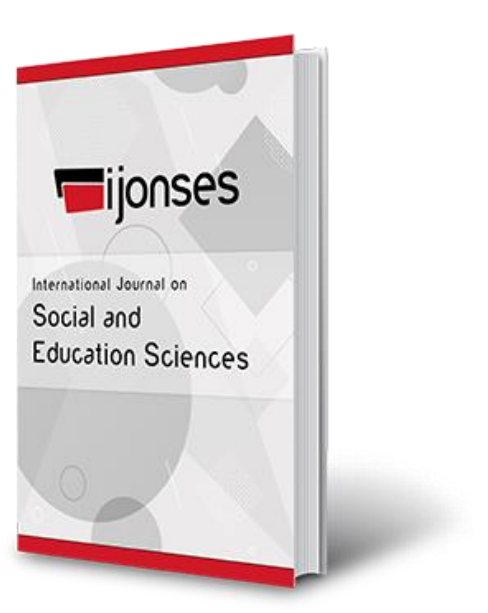

\title{
Comparing Computer-Based Programs' Impact on Problem Solving Ability and Motivation
}

\author{
Hannah Doster \\ University of North Georgia, USA \\ Josh Cuevas \\ University of North Georgia, USA
}

www.ijonses.net

\section{To cite this article:}

Doster, H. \& Cuevas, J. (2021). Comparing computer-based programs' impact on problem solving ability and motivation. International Journal on Social and Education Sciences (IJonSES), 3(3), 457-488. https://doi.org/10.46328/ijonses.121

\begin{abstract}
International Journal on Social and Education Sciences (IJonSES) is a peer-reviewed scholarly online journal. This article may be used for research, teaching, and private study purposes. Authors alone are responsible for the contents of their articles. The journal owns the copyright of the articles. The publisher shall not be liable for any loss, actions, claims, proceedings, demand, or costs or damages whatsoever or howsoever caused arising directly or indirectly in connection with or arising out of the use of the research material. All authors are requested to disclose any actual or potential conflict of interest including any financial, personal or other relationships with other people or organizations regarding the submitted work.
\end{abstract}

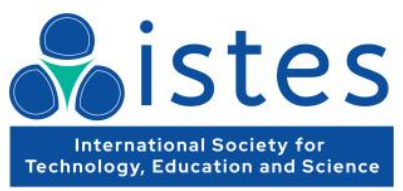




\title{
Comparing Computer-Based Programs' Impact on Problem Solving
}

\section{Ability and Motivation}

\author{
Hannah Doster, Josh Cuevas
}

\begin{tabular}{|c|c|}
\hline Article Info & Abstract \\
\hline $\begin{array}{l}\text { Keywords } \\
\text { Computer-based programs } \\
\text { Elementary mathematics } \\
\text { Student motivation } \\
\text { Problem solving } \\
\text { Computer-assisted } \\
\text { instruction }\end{array}$ & $\begin{array}{l}\text { Teaching mathematics involves a variety of techniques and approaches in order } \\
\text { to reach students' academic needs in a way that aids them in achieving at the } \\
\text { level required by state standards. One of the ways that educators are meeting the } \\
\text { needs of their students is through using computer-based programs. In this study, } \\
17 \text { fifth grade students were placed into two groups and assigned computer- } \\
\text { based programs. One program, MobyMax, offered students scaffolding measures } \\
\text { to aid in concept development. The other program, IXL, offered students } \\
\text { detailed feedback in response to their answer submissions. This study was } \\
\text { designed to determine the impact of the features of the two computer-based } \\
\text { programs on student achievement through problem solving and their level of } \\
\text { motivation. Students in both groups experienced gains in problem-solving ability } \\
\text { on average, while it appeared that those who received instruction through } \\
\text { MobyMax benefitted more. Time spent on the program did not appear to be a } \\
\text { contributing factor to gain score for problem solving. And student motivation } \\
\text { showed little change throughout using either computer-based program. }\end{array}$ \\
\hline
\end{tabular}

\section{Introduction}

In elementary schools around the world, students are learning foundational mathematics concepts through innovative means every day. Teachers of mathematics have a multitude of strategies and tools at their fingertips to best serve their students. According to the National Council of Teachers of Mathematics (2000), technology must be an integral part of mathematics instruction. There exist many reasons to use technology in the mathematics classroom. Even more than the number of reasons to use technology in the classroom is the options that can be used to accomplish the task of meeting students' needs in math. Mathematics tools vary greatly but generally contain essential elements which can aid in developing students' mathematical understanding.

\section{Computer Programs in Math Instruction}

Rationale

Teachers and schools choose to use technology and mathematical programs in classrooms for a wide variety of reasons. According to the National Council for Teachers of Mathematics (2000), teachers need to use technology in the classroom because of the versatility that it allows. Teachers are able to create assignments or 
post lessons for students to utilize while working independently. Teachers are also able to individualize instruction through the use of technology and mathematical programs. Differentiation is an important element of education, and technology use makes meeting students' individual needs more attainable for teachers. Smith (1973) found that when students used computer assisted instruction that they were more self-aware of their math ability than they were prior to using this type of instruction. This self-awareness aids students in strengthening areas of weakness. Additionally, research suggests that using technology in the mathematics classroom increases student engagement even with difficult content (Drickey, 2006; Fital-Akelbek \& Akelbek, 2012; Ravenel, et al., 2014).

Neill and Matthews (2009) found that using computer programs to support mathematics instruction aided students who were performing below grade-level to get closer to meeting grade level standards. Similarly, Symington and Stranger (2000) found that when using a variety of mathematical programs in the classroom students with disabilities were able to be more independent in expression of their mathematical understanding. As the students gained their feelings of independence, the teachers were also able to raise their expectations for these particular students which brought them closer to performing similarly to their academic peers of average ability. Overall, it is reasonable to conclude that technology and computer-based programs are becoming essential in aiding students to develop mathematical understandings through personalization, self-awareness, engagement, independence, and high expectations.

\section{Utilization}

Teachers and schools have an abundance of options when it comes to choosing how they will utilize technology and computer programs to support mathematics instruction. One option that teachers have to use technology and computer programs to enhance mathematics instruction is to utilize it for fact fluency. Musti-Rao and Plati (2015) found that when using technology to reinforce fact fluency in multiplication that students were able to complete more problems in one minute than by using a teacher directed strategy. Hassler Hallstedt, et al. (2018) and Kiger, et al. (2012) found similar results in relation to fact fluency when working with second graders on addition and subtraction and third graders on multiplication fluency, order respectively, with tablet apps. Rich, et al. (2017) also found that using computer-based instruction aided in fact fluency and that this fluency translated onto paper-based and computer-based assessments. Burns, et al. (2012) indicated that computer-based fact fluency practice supports students who are identified to be "at risk" or having severe deficits. Overall, research supports using computer-based instruction to aid with fact fluency.

Additionally, students and teachers preferred using the technology for reinforcement due to accessibility and convenience. In addition to fact fluency, teachers may choose to use technology as a means of presenting students with manipulatives. Drickey (2006) provided students with the opportunity to use virtual manipulatives during math instruction via a computer-based program. Students enjoyed being able to use the virtual manipulatives because it allowed them to express more creativity than physical manipulatives and made them feel that they had a better understanding of mathematical concepts than using no manipulatives at all. Additionally, it was noted during the research that students using the virtual manipulatives exhibited the most 
on-task behavior out of the three groups in the study. Another option for teachers to utilize technology in the mathematics classroom is in making instruction interdisciplinary. Symington and Stranger (2000) found that by incorporating a variety of computer-based programs into mathematics instruction that students were exposed to rigorous reading about math which aided students in being able to have more thoughtful conversations and develop better writing about math. Technology and computer programs enable teachers to provide math instruction that is engaging and beneficial to students on multiple levels.

\section{Components of Computer Programs to Support Math Instruction}

Problem Sets

Computer programs that are designed to support math instruction consist of several common elements. One of those elements is the problem set. Choppin, et al. (2014) analyzed several computer programs designed to support mathematics instruction specifically in the elementary and middle grades. Each of the six programs that they chose to analyze had problem sets that were designed differently and were suited for different purposes. Some of the problem sets were designed to improve fact fluency, others were designed for concept development, while some were designed to develop mathematical reasoning. One of the programs that was the most well supported based on this research was Dreambox due to the data provided on student usage which aided teachers in determining the most effective strategies to use during guided instruction segments. Depending on the needs of the students, a teacher may choose to use a program based on the design of the problem sets.

\section{Adaptability}

A feature of computer programs that has unique application in the mathematics classroom is adaptability. Adaptability, as will be utilized in this study, is defined as the ability to personalize learning to meet the individual needs of students. Most computer-based programs that are designed to support mathematics instruction utilize adaptability features in order to provide unique learning experiences for students. Adaptation in these programs can be presented in a variety of ways. Crawford, et al. (2016) investigated the impact of different types of adaptations within computer programs for mathematics instruction. In their research, two types of tools, embedded and student selected, were used as adaptations. Embedded tools were automatically provided to students based on the responses that students input to problem sets. Tools were imbedded included narration, interactive elements, and visual aids. Student selected tools became available to students as they clicked on them within the program. Tools that students could choose to use included calculators, formula toolbars, dictionaries, and help requests. Typically, students used these tools as they felt that they needed them. For this study, students were given a pre-test to examine ability in the mathematics content before using either program, and a post-test measure was administered for comparison. Students who exhibited low ability on the pre-assessment tended to use the student selected tools the most. Additionally, these same students were able to make gains in the content which were equivalent to the gains made by their average and high ability peers. By giving students the opportunity to choose to use the tools, they were able to guide the help as they needed it.

In another study, Higgins, et al. (2016) examined the use of tools for adaptability on students' mathematical 
reasoning ability. In this case, the researchers found that by utilizing specifically a dictionary tool and a help button, students were able to improve their mathematical reasoning ability. By placing control of elements of the programs into the hands of the students, students were able to find and utilize what they needed in order to be successful in their mathematical endeavors. In addition to tools available to students, computer programs to support mathematical instruction can also be adapted to individualized student instruction. In a study by $\mathrm{Ku}$, et al. (2007), researchers studied the impact of incorporating student interests into the programs. Students were provided with an interest survey which motive computer program then utilized to design problem sets that incorporated student interests individually so that each student had a custom problem set. Students who received the treatment of individualized instruction demonstrated a greater level of growth than their peers who did not use the personalized program. These students also achieved a higher mean score than their peers who did not receive the individualized treatment. These results indicate that by utilizing a program that invests in student interests, students are more interested and have a better attitude about learning math.

\section{Student Feedback}

One of the crucial elements of any computer program designed to support mathematical instruction is student feedback. Student feedback is the response of the program to the inputs that students provide in the form of answers to problem sets. Student feedback can be offered in a variety of formats depending on the design of the program. Roschelle et al. (2010) conducted a study in which a program that provided feedback to small groups was compared to a program with feedback to individual students. The researchers found that the program that utilized group feedback in the form of a colored chart indicating the number of attempts it took for small groups of students to correctly complete a problem set was beneficial in that it promoted collaboration between students and encouraged mathematical reasoning discussions. In this case, students and the teacher preferred the group feedback model for students.

Not all programs offer group feedback, though. More often than not, programs provide individual students with feedback. Some programs utilize gamification in their problem sets in order to improve student engagement and academic achievement (Carr, 2012; Traynor, 2003). By using gamification, programs incorporate games into their design for the problem sets in which students have to correctly answer problems in order to move on in the game. If students do not answer questions correctly, they will have to participate in more practice and problem sets to correct their misunderstandings before they will be presented with opportunities to engage in play. As students answer individual problems and complete problem sets correctly, they are provided with more opportunities to engage in the game elements of the programs. In this way, the game portions of the programs serve as positive reinforcement and many students enjoy this element.

Some computer programs designed to support mathematical instruction offer different types of feedback to individual students, as well. Kramarski and Zeichmer (2001) compare the use of programs which provided feedback to students in the forms of metacognitive feedback and result feedback. Students who received metacognitive feedback were prompted after incorrect answers with a list of questions in order to elicit a thought process for why the answer that they supplied was incorrect. Students who received the result feedback were 
given responses that simply noted if the response to the problem set was correct or incorrect. The researchers found that when students were provided with metacognitive feedback they were able to complete more problems correctly and could explain their mathematical reasoning more than the students who had only received result feedback. The type of feedback that students receive and how the feedback is presented are essential and make a difference in the ability of the computer program to support mathematical instruction.

\section{Teacher Feedback}

A final element in the design of computer programs to support mathematical instruction is teacher feedback. Teachers need the ability to use information from the computer programs to inform their instruction. In the past, only teachers were provided with feedback from computer programs designed to support mathematical instruction which left students in the dark in terms of their progress in the programs (Penuel, et al., 2004). In further research, it was found that in order for teachers to truly utilize a computer program it has to be just as user friendly for the teachers as it is for the students. Teachers need the ability to be able to see reports of how their students are performing on the problem sets so that they can make decisions on how to further utilize the program and plan additional teacher-directed supports. Teacher feedback is also essential in demonstrating to teachers how students are utilizing a computer-based program (Higgins, et al., 2016). Through the teacher reports of many programs, teachers are able to recognize the ways that the programs are being adapted to meet the needs of the students in their class, whether that is through embedded adaptations or student selected tools. It is essential that computer-based programs provide teachers with feedback so that they can utilize the program to the best of its capabilities.

\section{Summary}

Research provides great insight into why technology and computer-based programs are necessary in supporting mathematical instruction. Students and teachers need this tool in order to provide personalized and engaging learning experiences that enhance the instruction that students are already receiving through teacher directed lessons. The technology and computer programs can be used to meet a variety of needs in the mathematics classroom. Additionally, each computer program offers different problem sets, adaptations, student feedback, and teacher feedback in order to create the best experience for students and teachers. These elements impact the way that students and teachers interact with a program and the effectiveness of its use on the students.

\section{Current Study}

In mathematics education, there exists a multitude of resources that educators, schools, and school systems can elect to use. Of those options, many educators are choosing to use online resources to enhance their mathematics instruction. When choosing an online mathematics program, school leaders have a variety of factors to keep in mind. Some considerations that school systems may take into account when choosing online mathematics programs include accessibility for students and teachers, user friendliness, features of the program, and standards alignment. Additionally, schools pay close attention to the cost of the program. Decidedly, cost is a 
determining factor in the purchase of a program, but how do educational leaders conclude that an online mathematics program is worth the financial investment? Effectiveness of the program ascertains its worth to the students, teachers, schools, and school systems.

Effectiveness of an online mathematics program stands as the most crucial factor in determining whether or not a school system will choose to use and purchase a program. One possible measure of effectiveness of a mathematics program is the ability of the program to assist students in problem solving. In this study, problem solving was defined as the ability to use the provided information to find solutions to mathematical problems. As stated previously, schools have a multitude of options for online mathematics problems which require students to employ problem solving strategies. Two of these programs are IXL and MobyMax. This study examined both of these mathematics programs to answer the following questions:

1. Did fifth grade students improve their problem solving abilities from using IXL or MobyMax as programs to support mathematics instruction?

2. Was IXL or MobyMax more effective in supporting fifth graders ability to problem solve in math?

3. Was there a relationship between time spent using IXL or MobyMax and improvement in mathematical problem solving for fifth graders?

4. Was there a difference between the level of motivation that students using IXL experience versus those students using MobyMax?

\section{Method}

\section{Contextual Factors}

The study took place at an elementary school in northeast Georgia. The school was located in a rural county with an estimated population of 67,519 (United States Census Bureau, 2017). In the school district, four out of six of the elementary schools were considered Title I schools. The school in which the study took place was one of these schools. Over half of the students in this school came from low-income families with almost 55\% qualifying for free or reduced lunch (Georgia Department of Education, 2017). During the 2017-2018 school year, the school had the following ethnic and racial demographics: 18\% Hispanic, 66\% White, and the remaining 17\% comprised of Indian, Asian, Black, Pacific Islander, and Multiracial students.

In this study, the participants were in a fifth grade class of identified gifted and high achieving students. The students were taught by a two-teacher team, and students were grouped based on academic ability. The class of students that was used for the study demonstrated high academic ability in mathematics on a quarterly benchmark assessment which was selected by the school system. The students were taught mathematics by one gifted certified educator. The class was comprised of 20 students with 6 males and 14 females, though ultimately the analyses were confined to 17 students. Within the class, $75 \%$ of the students were White, $10 \%$ Hispanic, and 15\% Multiracial. Of the 20 students, seven students, three males and four females, were identified as gifted. One of the students is served through ESOL. The students ranged in age from 10-11 years old. Within the class, the students were placed into one of two groups based on matched pairs design. Each group was comprised of 10 students. In the first group, which received the IXL treatment, 7 of the students were male and 
3 were female. In this same group, $70 \%$ of the students were White, $20 \%$ Multiracial, and $10 \%$ Hispanic. Two of these students were identified as gifted and one student was served through ESOL. In the other group, which received the MobyMax treatment, there were 7 males and 3 females. Of the students in this group, 80\% were White, 10\% Multiracial, and 10\% Hispanic. Five of the students in this group were identified as gifted.

\section{Materials and Measures}

IXL

For the study, students were assigned using matched pairs design to one of two online computer programs. One of the programs was IXL and, according to IXL's company website (2018), this computer program was designed using Common Core State Standards to be an adaptive tool to challenge students through rigorous problems and concept development which could be used with any instructional model to help students to develop fluency. Unlike the other computer program, problem sets did not provide students with scaffolding before answering questions. Students may have been presented with questions in word problem, modular, computational format, or a combination of the prior listed formats. In the word problem sets, students were presented with a real life situation in which they had to use the math that they learned in class in order to solve the problem. For the modular questions, students were presented with a model to represent an equation or concept. In the computational questions, students were presented with equations that they had to solve. Regardless of the question type, the students had to respond in either selected response or open-ended format. These question types as previously described may have been combined to formulate a question in the problem set, as well.

In IXL, if students incorrectly answered problems, they were provided with a review of the way they answered the problem, a "remember" section which explains the concept of the problem, and the correct answer with stepby-step instructions on how to correctly answer the problem. First, students were provided with the problem again and the solution that they entered. Next, students were presented with a "remember" section in which the concept was explained through writing. Finally, students were provided with the solution and instructions on how to correctly complete the problem. If a student solved a problem incorrectly, they were presented with stepby-step equations, models, or computation that explained each step in the context of the problem. If students incorrectly answered problems, the level of difficulty decreased until students were able to correctly answer a problem, and the program provided suggestions of earlier problem sets for students to review. Also in IXL, if students correctly answered the problem, they were provided with a message of praise such as "Good work!" As students continued to correctly answer problems, the problems increased in rigor. Students earned points for their "smart score" based on correct answers to problems but lost points when problems were answered incorrectly. When students obtained a smart score of 100, students were considered to have reached mastery of the assigned problem set.

MobyMax

The other computer program that students used was MobyMax. In a report published by the company, 
MobyMax was said to utilize basic cognitive skills, like fluency, to develop concepts which were monitored through extensive formative assessments (2X Learning, 2018). Unlike in IXL, the first lesson provided students with scaffolded problem sets based on their assessments within the program which provided step-by-step examples of how to solve the problems. This scaffolding was first demonstrated through a short "teach me" video at the beginning of each lesson which explained the concept and provided step by step instructions on how to complete the problem sets. Then as students were able to complete problem sets, less scaffolding was provided to students so that by the time they reached the final lesson in the problem set, scaffolded supports were no longer available to the student. Problems could have been provided in word problem, pictorial, or computational format. Some questions asked students to supply a typed response, while other questions required students to choose from a list of answers in order to provide a solution. By providing students with this type of format for the problem sets, the goal, according to the company's website, was to aid students in developing number sense and automaticity in problem solving.

In MobyMax, if students correctly answered questions, they proceeded to more questions. If students did not correctly answer a question, they were provided with the correct answer and equations to demonstrate how to correctly solve the problem. Some questions provided students with more than one opportunity to correctly answer the question. When students answered five problems, they were provided with a percentage score. If students did not reach a minimum percentage score, they were provided with an additional lesson to complete that day. If students did reach the minimum percentage score, they were provided with an online badge and game time within the program. Teachers were able to access reports on individual and class progress in real time in order to monitor student usage and progress.

\section{Data Collection}

As a pre- and post-measure of student progress, students took an assessment on solving mathematical problems based on the Common Core State Standards through the Eureka Math Curriculum. The assessment, which was taken on paper, was composed of twelve problems. All of the problems that students were asked to solve were presented in a computational format in which students had to generate their own response. Student answers were strictly scored based on incorrect and correct responses to problems, rather than receiving partial credit for some correct computation. Please see Appendix A for a copy of the assessment used. Additionally, student usage and progress was monitored using the internal reports on both computer programs. From these reports, the amount of time that students spent on the programs was noted in order to make a comparison between usage and gain scores on the post-measure of student progress.

In order to measure student motivation, the MRQ, Motivation for Reading Questionnaire, was used (Wigfield \& Guthrie, 1997). To use this questionnaire for the purposes of this study, the word "reading" in each of the prompts was changed to "math" in order to measure motivation for math. This questionnaire was composed of 53 Likert-type items in which students rated statements on a scale of one to four. If students felt that they disagreed with a statement, their response was closer to one. If a student felt that they agreed with a statement, they rated it closer to four. All of the items of the questionnaire were organized into eleven constructs of 
motivation including: efficacy, challenge, curiosity, involvement, importance, work avoidance, competition, recognition, grades, social reasons, and compliance. As reported by the authors, the MRQ has reliability statistics ranging from .43 to .81 . Students participated in the motivation questionnaire at the beginning and ending of the intervention period to compare how students' math motivation changed over the intervention period and to compare the motivation that students experienced at post measure based on the program to which they were assigned. Please see Appendix B for a copy of the MRQ as it was edited to fit this study.

\section{Procedures}

Pre-assessment

After obtaining IRB approval and consent for participation, students were administered a pre-assessment to help in determining the prior knowledge that students had of multiplication and division of fractions and decimals. This pre-assessment assessed students' knowledge before this content had been taught according to the pacing guide provided to fifth grade math teachers by the school system. This pre-assessment was composed of openended questions in computational format. The assessment was graded on a strictly incorrect and correct basis. Using the scores from the pre-assessment, students were placed through matched-pairs design into two experimental groups. Students were matched based on their score on the pre-assessment. The two students with the lowest scores were matched, then one student was placed into the IXL experimental group and the other student was placed into the MobyMax experimental group. Then the next two lowest scores were matched and one student was placed into the MobyMax group while the other was placed into the IXL group. This process continued of matching scores and placement into groups until all students were assigned to either the MobyMax or IXL treatment group. Additionally, each student took the MRQ to measure their math motivation prior to beginning the treatment. This questionnaire was not typically completed by students during math class time but was allowed during this class period for research purposes.

\section{IXL Group}

In this experimental group, students were assigned to work on IXL. In this group, students received guided instruction from the educator during math workshop. After students worked with the educator during guided math, students worked on IXL. Students were provided with a typed list of assigned problem sets from IXL. These problem sets were based on the Common Core State Standard for fifth grade that the students were currently working on during their guided math rotation with the teacher. Students sat at a table and asked not to interact with peers while working on IXL. The students were provided with a slate and dry erase marker or pencil and paper, based on their preference, in order to work out problems that were presented in the problem set. Students worked on the problem sets independently. Any assistance provided by the educator was simply to direct students to resources within the program to use rather than demonstrating to students how to solve the problem or helping them to process the information in the problem. Typically, students had to review previous problem sets in order to review earlier content due to the lack of scaffolding before the problem sets in IXL. Additionally, students were directed to take note of the feedback that was provided to help them to answer future problem set questions. The teacher also monitored student progress by using the real time feature within 
IXL to ensure that students were on task and to direct guided math instruction during the math workshop. As students completed problem sets, they moved on to the next assigned problem set in the list provided by the educator. Students worked on IXL for 20 minutes, four times per week, for eight weeks. Additionally, students had the ability to access IXL at home. Some students chose to spend additional time on IXL at home to complete the assigned problem sets.

\section{MobyMax Group}

In this experimental group, students were assigned to work on MobyMax. In this group, students worked on their assigned treatment before receiving guided instruction from the educator during math workshop. Students sat at a table and were asked not to interact with peers while working on MobyMax. Once students logged into the program they accessed the assignment tab at the top of the screen where there were notifications of assigned problem sets in MobyMax. Students clicked on the assignment which revealed problem sets based on the Common Core State Standard for fifth grade that the students were currently working on. The student were provided with a slate and dry erase marker or pencil and paper, based on their preference, in order to work out problems that were presented in the problem set. Students worked on the problem sets independently. When students first opened the problem set, the lesson provided students with a "teach me" video in which students received scaffolded instruction on how to complete the problems in the following lesson. After watching the video, the students began working on the lesson within the problem set. Any assistance provided by the educator was simply to direct students to resources within the program to use rather than demonstrating to students how to solve the problem or helping them to process the information in the problem. Typically, students had access to graphics which explained the questions within the problem set at the top of the screen. Additionally, students were directed to take note of the feedback that was provided to help them to answer future problem set questions. The teacher also monitored student progress using the real time feature within MobyMax to ensure that students were on task and to direct guided math instruction during the math workshop. As students completed lessons, they were allotted game time by the program. Students were allowed to work on the game time during their treatment period. Students worked on MobyMax for 20 minutes, four times per week, for eight weeks. Additionally, students had the ability to access MobyMax at home. Some students chose to spend additional time on Moby at home to complete the assigned problem sets. After students worked on their treatment for 20 minutes, they proceeded to their guided math group with the teacher.

\section{Post-assessment}

At the end of eight weeks, students were re-assigned the pre-test that they took before treatment to be used as a post measure for comparison. The post-tests were used to measure if students made improvements as a result of using the two computer math programs. Additionally, the scores from the test were used to compare how students in each group performed in comparison to one another. In addition to the post-test, student usage of the programs was addressed. The reports of usage were taken from both programs and the number of minutes used by each student was totaled. Additionally, students took the MRQ a second time for comparison to pretreatment (Wigfield \& Guthrie, 1997). 


\section{Results}

\section{Improvement in Problem Solving}

Figures 1 and 2 below show the data collected for each group, IXL and MobyMax, on the number of correctly answered problems on the pre and post math assessments with questions from the Eureka math curriculum. Each bar indicates the number of points the student scored on an assessment. On each figure, the left hand bar located above the student identification number indicates the number of correctly answered problems on the preassessment, while the bar on the right above the student identification number represents the number of correctly answered problems on the post assessment. In the cases of student 1 in the IXL group and student 1 in the MobyMax group, only a bar for the post-assessment is present due to the students correctly answering zero problems on the pre assessment.

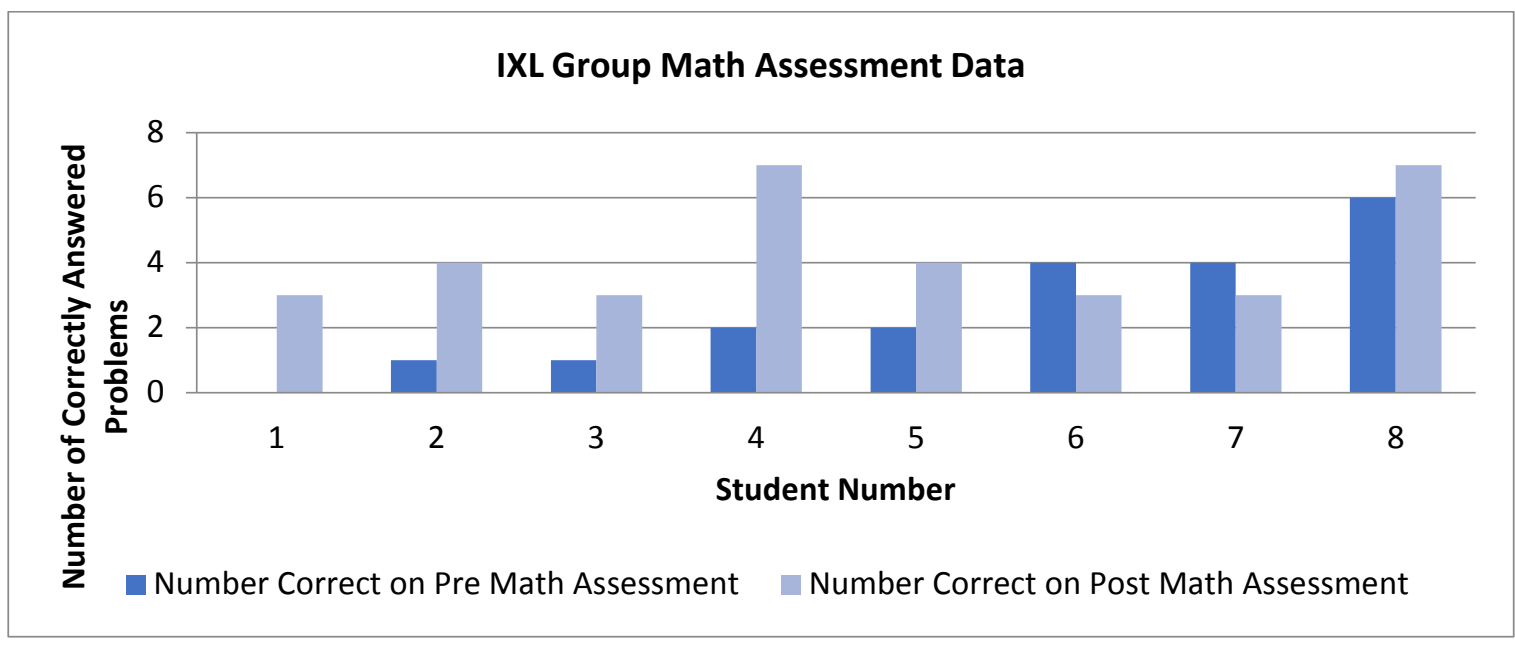

Figure 1. Pre and Post Math Scores for the IXL Group

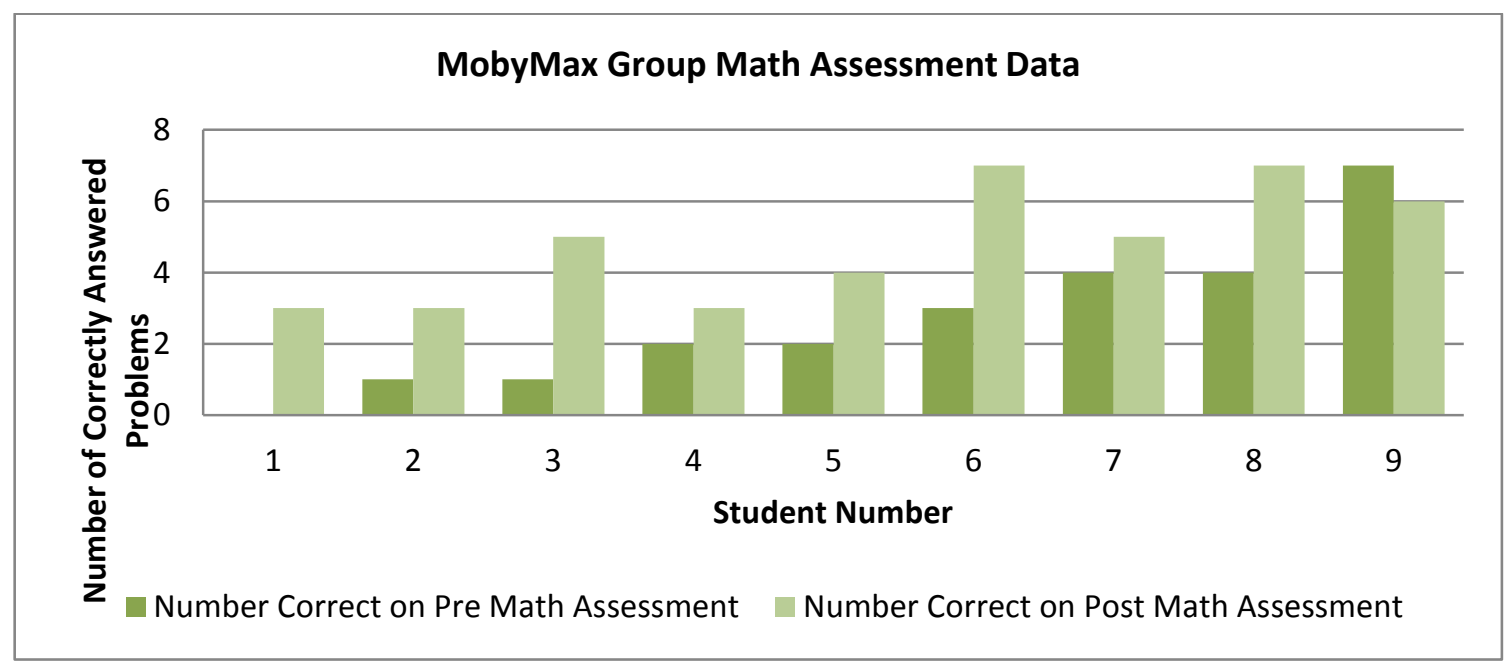

Figure 2. Pre and Post Math Scores for the MobyMax Group Math

In examining the specific scores for the IXL group, the average score on the math pre-assessment was 2.5 out of 12. On the math post assessment, the average score for this group was 4.25 . Out of the students in this group, six 
out of eight made at least one point higher in their score on the math assessment after the treatment period. The group overall showed 1.75 points of average improvement after receiving the treatment of IXL for eight weeks. In the MobyMax group, the average score on the math pre assessment was 2.67 out of a possible 12 points. On the math post assessment, students in the MobyMax group had an average score of 4.78. Of the students in the MobyMax group, eight out of nine students made at least one point higher in their score on the math assessment after using MobyMax. The MobyMax group demonstrated a difference in average scores on the pre and post assessment of 2.11 points which is a greater increase in average score than exhibited by the IXL group. In examining the first research question which asks if the use of computer-based programs improves students' problem solving ability, the data collected from both groups reflects an overall increase in students' problem solving ability over the course of the treatment period.

\section{Support in Problem Solving}

In Figures 3 and 4 below, each bar indicates the gain score on the math assessment with questions from the Eureka Math curriculum achieved by the students in each group.

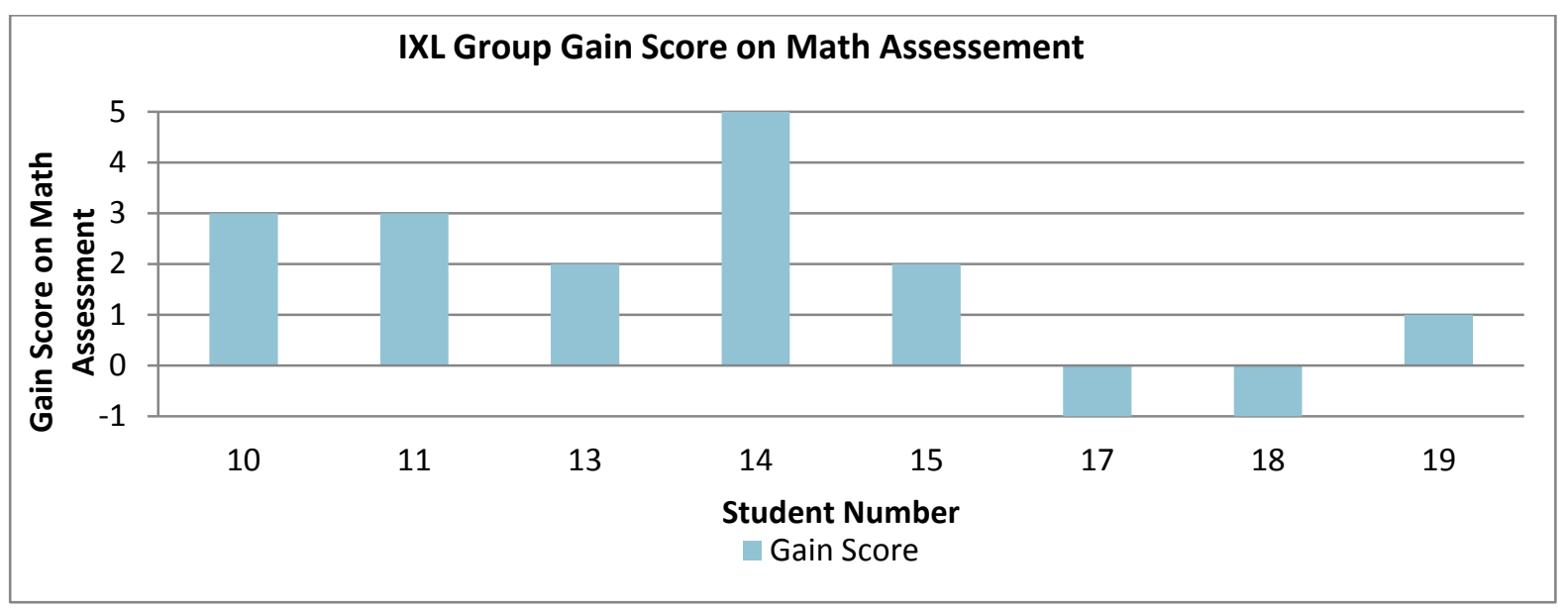

Figure 3. IXL Group Gain Scores on Math Assessment

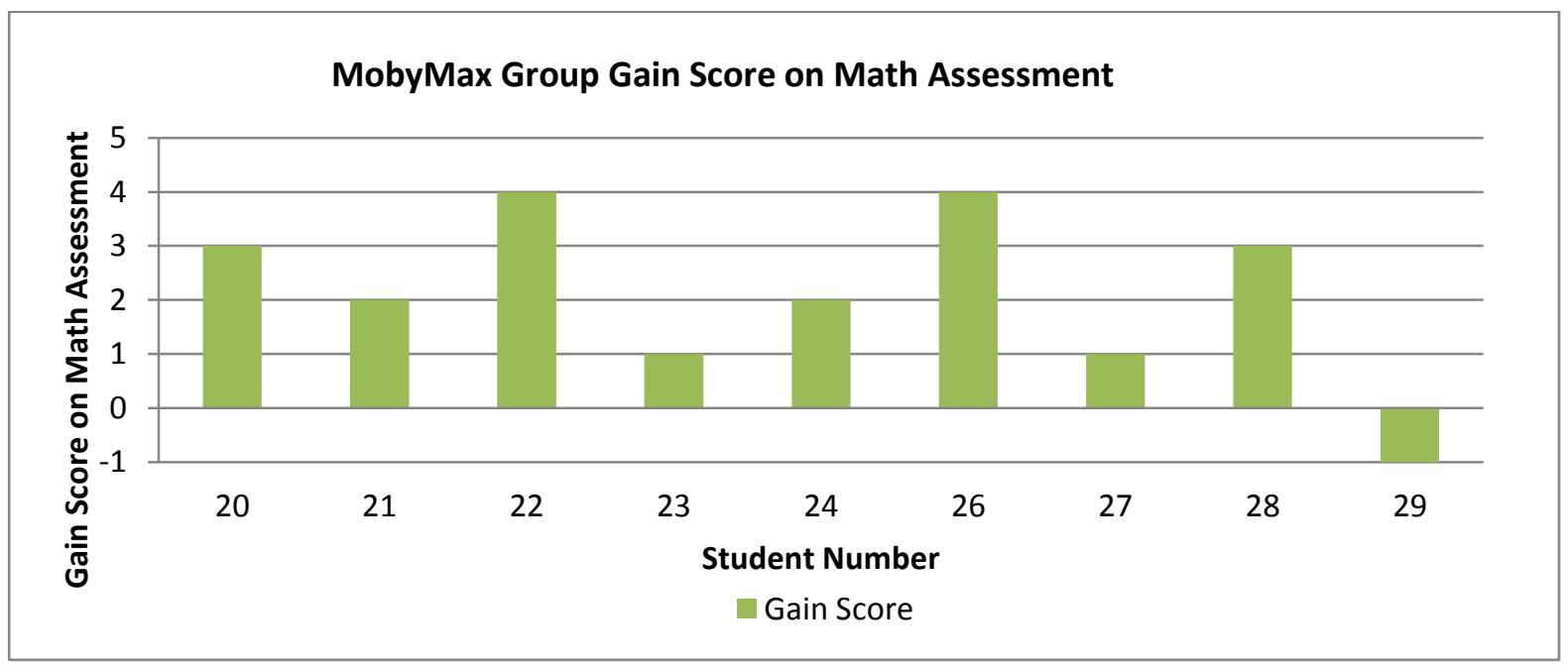

Figure 4. MobyMax Group Gain Scores on Math Assessment 
In examining the gain scores on the math assessment for each group, the gain scores ranged from negative one to five out of a possible score of twelve. In the IXL group, gain scores ranged from negative one to five, while in the MobyMax group, gain scores ranged from negative one to four. When looking at the number of students who made gains through use of their assigned treatment, six out of eight students obtained a positive gain score in the IXL group, while eight out of nine students in the MobyMax group obtained a positive gain score. Additionally, in the IXL group, five out of eight students correctly answered at least twice as many problems on the post-assessment according to Figure 1. In looking at Figure 2 and the MobyMax group data, five out of nine students correctly answered at least twice as many problems on the post-assessment.

The overall average gain score for both groups was 1.76. The average gain score in the IXL group was 1.75. In the MobyMax group, the average gain score was 2.11.These averages indicate that students in the MobyMax group experienced greater gains, a 0.36 difference in average gain scores between the two groups, from using this treatment versus the IXL group using their assigned treatment. In the IXL group, six students scored above the average gain score for the group. In the MobyMax group, four students scored above the average gain score for the group. Also of note is that the student who achieved the greatest gain of 5 was in the IXL group.

\section{Treatment Time Related to Gain Score}

In examining Figures 5 and 6 below, each data point indicates the gain score and time spent in minutes on their treatment program, IXL or MobyMax, by each student in their respective groups. As stated previously, the range in gain scores for students in both groups was negative one to five with the range specific to the IXL group being negative one to five and the range for the MobyMax group being negative one to four. The range in time spent by students on their respective programs was 186 minutes to 544 minutes. In the IXL group, the range of time spent on the program was 186 minutes to 414 minutes. In the MobyMax group, the range of time spent on the program was 402 minutes to 544 minutes. The average amount of time spent on the programs overall was 405.06 minutes. The average amount of time spent by students on IXL was 344.13 minutes, while the average amount of time spent by students on MobyMax was 459.22 minutes. Students in the MobyMax group spent more time on the program than the students in the IXL group.

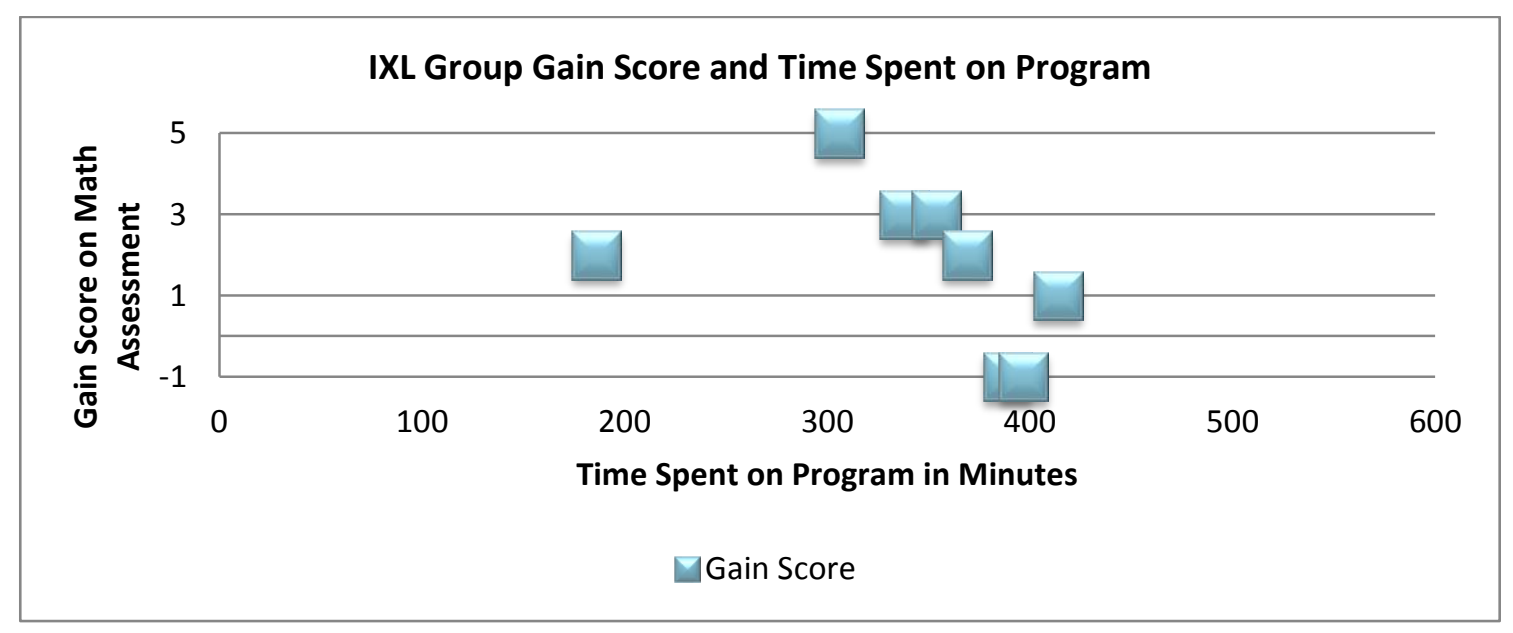

Figure 5. IXL Group Gain Score compared to Time Spent on Program 


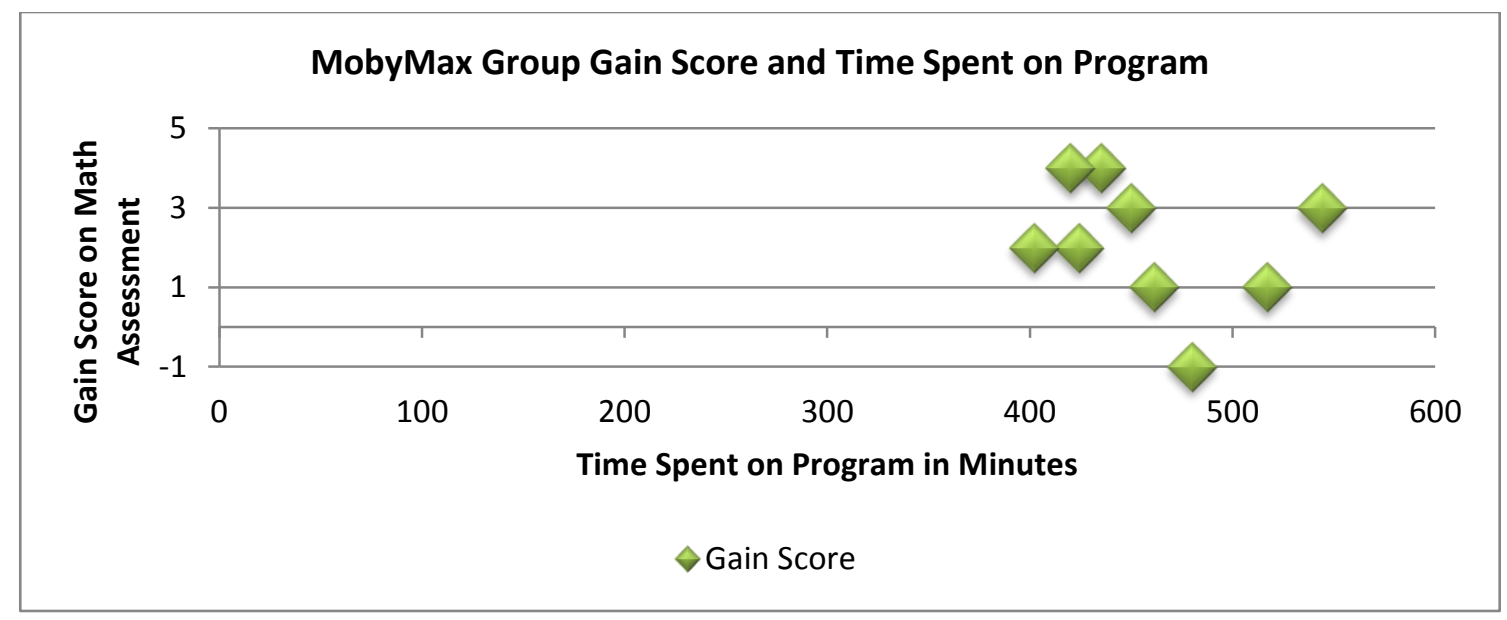

Figure 6. MobyMax Group Gain Score compared to Time Spent on Program

When examining the data points in Figure 5, it can be noted that the two students who experienced a negative gain score spent the second and third most amount of time on the program, and the student who spent the most time had the third lowest gain amount. The student who experienced the greatest gain score while using IXL spent the second least amount of time on the program. In looking at Figure 6, observations can be made that the student who achieved a negative gain score spent the third most amount of time on the program, while the students who achieved the highest gain score of 4 after working on MobyMax spent the second and fourth least amount of time on the program. The student who experienced the greatest gain score of 5, a member of the IXL group, spent the second least amount of time on the program of all of the students who participated in the study.

\section{Motivation Based on Program}

In Figures 7 and 8 below, each pair of bars indicates the overall score on the MRQ for Math that each student scored. Above each student identification number the left bar indicates the overall pre assessment score on the MRQ for Math that the student scored. The right bar above the student identification number indicates the overall post assessment score on the MRQ for Math that the student scored.

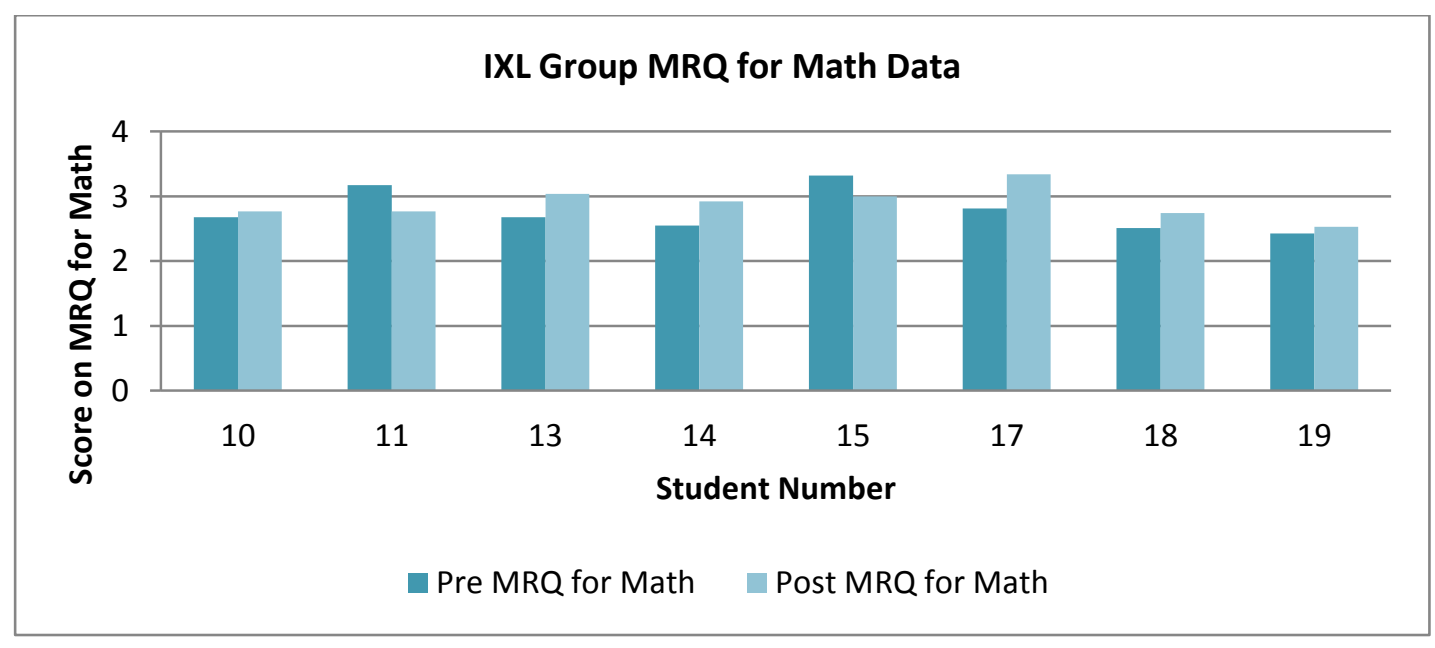

Figure 7. IXL Group Pre and Post Motivation Scores 


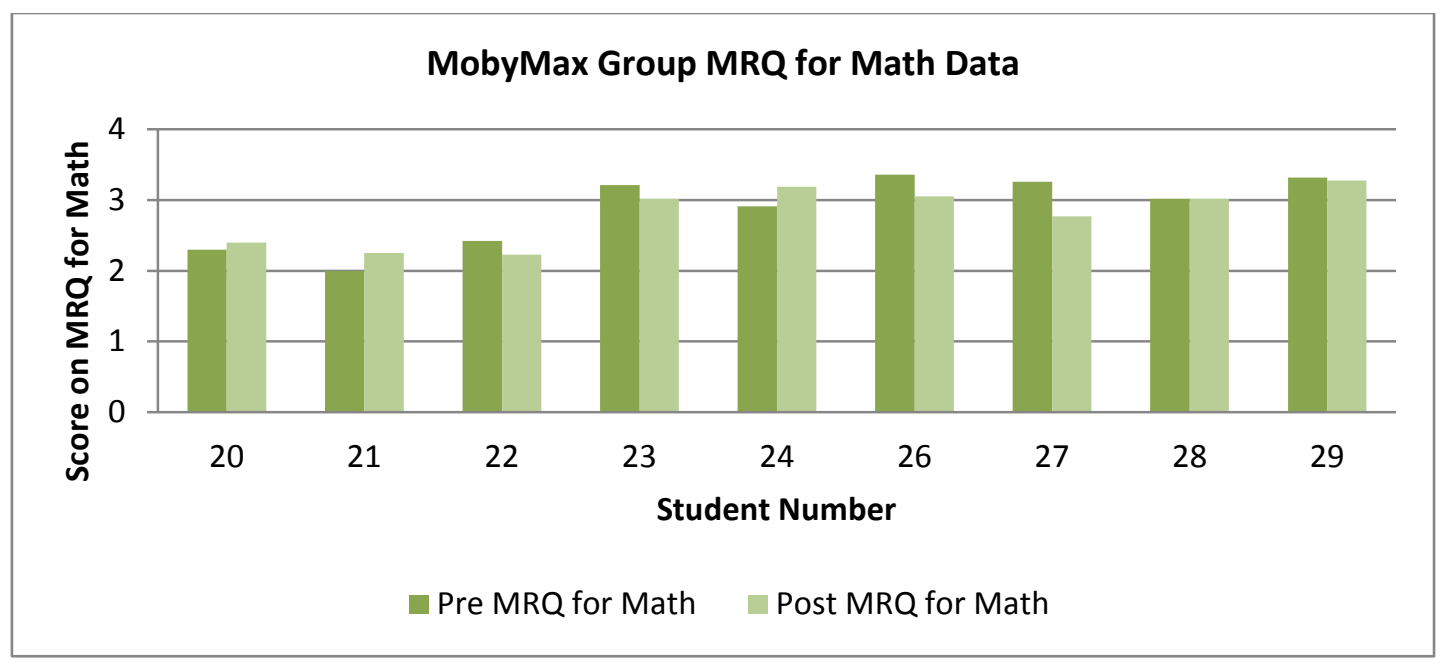

Figure 8. MobyMax Group Pre and Post Motivation Scores

The overall average score on the pre assessment for both groups on the MRQ for Math was 2.82, while the overall average score on the post assessment for both groups was 2.84 out of a possible 4 points. The difference in the overall average score was 0.02 from the pre to post assessment. In looking at the IXL group and Figure 7, the average overall score on the pre assessment was 2.77. The overall average score on the post assessment was 2.89 for this group. A difference in overall average scores on the pre and post assessment was 0.12 which indicates a slight increase in overall motivation for this group. This difference in overall average score on the MRQ for Math was greater than the difference for all of the students collectively. In this group, six out of eight students obtained scores which indicate slightly increased levels of overall motivation on the post-assessment measure.

When examining the data from the MobyMax group and Figure 8, the average overall score on the pre assessment was 2.87, while the overall average score on the post assessment was 2.80. The difference between the overall average score on the MRQ for Math was -0.07. This difference was less than the change found in overall motivation for the IXL group and both groups collectively. In the MobyMax group, three out of nine students obtained scores which indicated an increased level of motivation after working on MobyMax. Of the other six students in the group, five students' scores showed slightly decreased motivation after working on MobyMax.

\section{Discussion}

The focus of this study was to determine the impact of the use of computer-based programs, specifically IXL and MobyMax, on student achievement through problem solving ability and motivation in the elementary mathematics classroom. Based on prior research, the prediction was that students who used computer-based programs would improve their problem solving ability over the treatment period (Burns, et al., 2012; Hassler Hallstedt, et al., 2018; Kiger, et al., 2012; Musti-Rao \& Plati, 2015; Rich, et al., 2017). In this research, the computer-based programs helped the majority of students to improve their problem solving ability as indicated through the gain scores on the math assessment. 
Additionally, this study sought to find out if one computer-based program better supported students in problem solving ability compared to the other program. In this case, the gain scores on the math assessment were used for comparison. The results suggest that MobyMax may have been better at supporting student problem solving ability for this particular group of students due to the fact that students in this group experienced a higher average gain score than the students in the IXL group. It is of note that the average gain score for the MobyMax group was above that of all the participants, while the IXL group maintained an average gain score which was below that of the collective group. Additionally, only one student in the MobyMax group experienced a negative gain score, while two students in the IXL group experienced the same result. A factor that may have contributed for the higher average gain score and fewer negative gain scores in the MobyMax group may be the scaffolding which was offered by this computer-based program. Previous research from Crawford, et al. (2016) and Higgins, et al. (2016), indicated that adaptability of a program aided in student academic achievement. In the case of MobyMax, this program offered scaffolding and tools which adjusted to the students' unique needs based on their performance in the problem sets. Unlike MobyMax, IXL did not offer these tools and adaptations in scaffolding which may explain the discrepancy in the gain scores.

A third factor that was considered in this study was the impact of usage on student problem solving ability. Based on the results, there did not appear to be a relationship between the amount of time spent on the computer-based programs and the gain scores achieved by the student. Several of the students who had the lowest gain scores spent the most amount of time on the computer-based programs, while students who had the highest gain scores spent less time than the collective group on their respective programs. One factor that may explain these results is that both computer-based programs include reward features for students. In the case of MobyMax, students are able to earn game time and work on competitions with classmates which may distract them from completing their problem sets. In IXL, students are able to earn badges and awards which can also be a source of distraction while in the program. Although students in this study had assigned tasks to complete in their respective programs, students were able to access other content (i.e. other math topics) as a means of distraction or work avoidance.

A final aspect of note in this study was the impact of computer-based programs on student motivation towards math. In the research of Drickey (2006), students enjoyed being able to work on computer-based programs during math due to the creativity and depth of reasoning that they felt that it allowed for them to gain. Overall, however, the collective group of participants in this study demonstrated little change in their motivation. The IXL group did experience some growth in average overall motivation over the treatment period, while the MobyMax showed a decreased score in average motivation over the treatment period though both showed only slight shifts. One explanation for this discrepancy in motivation may be that students in the IXL group were able to continually progress through problem sets without having to stop for scaffolded lessons, like the MobyMax group.

\section{Limitations}

In this study, there were several limitations. One of the most obvious limitations was the small sample size. 
Only 17 students participated in this study which limits the results from being generalized. Another limitation was the ability students in this sample. All of the students in this study were identified gifted and talented students or those who experience high levels of achievement in mathematics. Due to the fact that all students in this study were identified as having high mathematic ability, the results of this study cannot be generalized to populations of students of average or below average ability in mathematics. A third limitation in this study is the length of the treatment period. In this case, the treatment period was a short eight weeks.

A unique limitation to this study was that the computer-based programs provided scaffolding, in the case of MobyMax, and feedback, in the case of IXL, that taught students to complete problems with different strategies than the strategies that were being taught by the educator. In the computer-based programs, students were required to use specific strategies in completing the problem sets due to the expected response format which conflicted with the strategies taught by the educator. An example that frequently occurred during the treatment period was that the computer-based programs expected students to submit responses with improper fractions or fractions that had not been simplified, while only simplified fractions and mixed numbers were accepted by the educator. In some cases, the differences in guidance from the computer-based programs and the educator created confusion and led to misconceptions for the students in how to complete the problems.

\section{Implications}

In future research, the sample size of students and the length of the study should be increased in order to produce more generalizable results. Ideally, a study would be conducted over an entire school year to determine if different topics within mathematics yield different results. Additionally, students of all ability levels should be included in the study to ascertain if students of different ability levels experience different levels of achievement or motivation when using the computer-based programs. Future researchers may also consider aligning the strategies that are used in the computer-based programs and the direct instruction from the educator. In this case the researcher may need to select computer-based programs that exclusively use the preferred strategies of the educator or modify the strategies used during direct instruction to match the strategies taught in the computerbased programs.

Future researchers may be interested in exploring the impact of computer-based math programs which utilize gamification, such as Prodigy. Do computer-based programs that utilize gamification aid students in reaching higher levels of problem solving ability than computer-based without gamification? How do computer-based programs that utilize gamification impact student motivation toward mathematics? Perhaps answering these questions could help in reaching students of all ability levels.

\section{Conclusion}

There is still much to discover about the impact of computer-based programs on problem solving ability and motivation toward mathematics for students. With technology, instructional strategies, and students who are constantly changing, this topic will likely need continual research. Ultimately, there may not be a computer- 
based program that is a best fit for all students in meeting their academic and engagement needs, but finding a variety of programs that meet students' needs individually should be a priority in each mathematics classroom.

\section{Acknowledgements}

This study meets ethical standards and was approved by the IRB at the University of North Georgia and the participating public school. There was no funding to report. There are no conflicts of interest to report.

\section{References}

2X learning: Principles of scientific based research in MobyMax. (2018). Retrieved from https://data.mobymax.com/mc/documents/MaxMax\%20Research-Based\%20Pedagogy.pdf

Burns, M. K., Kanive, R., \& DeGrande, M. (2012). Effect of a computer-delivered math fact intervention as a supplemental intervention for math in third and fourth graders. Remedial and Special Education, 33, 184-191.

Carr, J. M. (2012). Does math achievement “h'APP'en" when iPads and game-based learning are incorporated into fifth-grade mathematics instruction? Journal of Information Technology Education: Research, 11, 269-286.

Choppin, J., Carson, C., Borys, Z., Cerosaletti, C., \& Gillis, R. (2014). A typology for analyzing digital curricula in mathematics education. International Journal of Education in Mathematics, Science and Technology, 2(1), 11-25.

Crawford, L., Higgins, K. N., Huscroft-D'Angelo, J. N., \& Hall, L. (2016). Students' use of electronic support tools in mathematics. Educational Technology Research and Development, 64(6), 1163-1182.

Drickey, N. (2006). Learning technologies for enhancing student understanding of mathematics. International Journal of Learning, 13(5), 109-116.

Fital-Akelbek, S., \& Akelbek, M. (2012). Smart use of technology in mathematics. International Journal of Technology, Knowledge \& Society, 8(4), 65-72.

Georgia Department of Education. (2017). Free and reduced price eligibility. Retrieved from https://oraapp.doe.k12.ga.us/ows-bin/owa/fte_pack_frl001_public.entry_form

Hassler Hallstedt, M., Klingberg, T., \& Ghaderi, A. (2018). Short and long-term effects of a mathematics tablet intervention for low performing second graders. Journal of Educational Psychology. https://doiorg.libproxy.ung.edu/10.1037/edu0000264.supp

Higgins, K. N., Crawford, L., Huscroft-D'Angelo, J., \& Horney, M. (2016). Investigating student use of electronic support tools and mathematical reasoning. Contemporary Educational Technology, 7(1), 1-24.

IXL for Schools. (2018). Retrieved from https://www.ixl.com/membership/educators/why-ixl

Kiger, D., Herro, D., \& Prunty, D. (2012). Examining the influence of a mobile learning intervention on third grade math achievement. Journal of Research on Technology in Education, 45(1), 61-82.

Kramarski, B., \& Zeichner, O. (2001). Using technology to enhance mathematical reasoning: Effects of feedback and self-regulation learning. Educational Media International, 38(2/3), 77-82. doi:10.1080/09523980110041458 
Ku, H., Harter, C. A., Liu, P., Thompson, L., \& Cheng, Y. (2007). The effects of individually personalized computer-based instructional program on solving mathematics problems. Computers in Human Behavior, 23(3), 1195-1210. doi:10.1016/j.chb.2004.11.017

Musti-Rao, S., \& Plati, E. (2015). Comparing two classwide interventions: Implications of using technology for increasing multiplication fact fluency. Journal of Behavioral Education, 24(4), 418-437. doi:10.1007/s10864-015-9228-x

National Council for Teachers of Mathematics. (2000). Principles and standards for school mathematics. Reston, VA: Author.

Neill, M., \& Mathews, J. (2009). Does the use of technological interventions improve student academic achievement in mathematics and language arts for an identified group of at-risk middle school students?. Southeastern Teacher Education Journal, 2(1), 57-65.

Penuel, W. R., Tatar, D. G., \& Roschelle, J. (2004). The role of research on contexts of teaching practice in informing the design of handheld learning technologies. Journal of Educational Computing Research, 30(4), 353-370.

Ravenel, J., Lambeth, D. T., \& Spires, B. (2014). Effects of computer-based programs on mathematical achievement scores for fourth-grade students. Journal on School Educational Technology, 10(1), 8-21.

Rich, S. E. H., Duhon, G. J., \& Reynolds, J. (2017). Improving the generalization of computer-based math fluency building through the use of sufficient stimulus exemplars. Journal of Behavioral Education, 26(2), 123-136.

Roschelle, J., Rafanan, K., Bhanot, R., Estrella, G., Penuel, B., Nussbaum, M., \& Claro, S. (2010). Scaffolding group explanation and feedback with handheld technology: Impact on students' mathematics learning. Educational Technology Research and Development, 58(4), 399-419.

Smith, I. D. (1973). Impact of computer-assisted instruction on student attitudes. Journal of Educational Psychology, 64(3), 366-372. doi:10.1037/h0034608

Symington, L., \& Stanger, C. (2000). Math equals success. TEACHING Exceptional Children, 32(4), 28-32.

Traynor, P. (2003). Effects of computer-assisted-instruction on different learners. Journal of Instructional Psychology, 30(2), 137-143.

United States Census Bureau. (2017). Quick facts. Retrieved from https://www.census.gov/

Wigfield, A. \& Guthrie, J.T. (1997). Relations of children's motivation for reading to the amount and breadth of their reading. Journal of Educational Psychology, 89, 420-432.

\section{Author Information}

\begin{tabular}{ll}
\hline Hannah Doster & Josh Cuevas \\
(iD http://orcid.org/0000-0002-8188-8093 & iD http://orcid.org/0000-0003-3237-6670 \\
University of North Georgia & University of North Georgia \\
3820 Mundy Mill Rd. & 3820 Mundy Mill Rd. \\
Oakwood, GA 30566 & Oakwood, GA 30566 \\
USA & USA \\
& Contact e-mail: josh.cuevas@ung.edu \\
\hline
\end{tabular}




\section{Appendix A}

Name

Date

1. Multiply or divide. Draw a model to explain your thinking.
a. $\frac{1}{3} \times \frac{1}{4}$
b. $\frac{3}{4}$ of $\frac{1}{3}$

c. $\frac{3}{4} \times \frac{3}{5}$

d. $4 \div \frac{1}{3}$

e. $5 \div \frac{1}{4}$

f. $\frac{1}{4} \div 5$ 
2. Multiply or divide using any method.

a. $1.5 \times 32$

b. $1.5 \times 0.32$

e. $12.8 \times \frac{3}{4}$

f. $\quad 102.4 \div 3.2$

EUREKA

Module 4:

Multiplication and Division of Fractions and Decimal Fractions 


\section{Appendix B}

Name

Date

Teacher

\section{Motivations for Math Questionnaire}

We are interested in your motivation for math.

The sentences tell how some students feel about math. Listen to each sentence and decide whether it talks about a person who is like you or different from you. There are no right or wrong answers. We only want to know how you feel about math.

For many of the statements, you should think about the ways that you complete math in your class.

Here are some ones to try before we start on the ones about math:

I like ice cream.

Very Different From Me

1
A Little Different From $\mathrm{Me}$

2
A Little Like Me 3
A Lot Like Me

4

If the statement is very different from you, circle a 1 .

If the statement is a little different from you, circle a 2.

If the statement is a little like you, circle a 3 .

If the statement is a lot like you, circle a 4.

I like spinach.

\section{Very Different From Me}

1
A Little Different From
Me

2
A Little Like Me
A Lot Like Me

4

If the statement is very different from you, what should you circle?

If the statement is a little different from you, what should you circle?

If the statement is a little like you, what should you circle?

If the statement is a lot like you, what should you circle?

Okay, we are ready to start on the ones about math. Remember, when you give your answers you should think about the things you are reading in your class. There are no right or wrong answers, we just are interested in YOUR ideas about math. To give your answer, circle ONE number on each line. The answer lines are right under each statement.

Let's turn the page and start. Please follow along with me while I read each of the statements, and then circle your answer. 
1. I like being the best at math.
Very Different From Me A Little Different From $\mathrm{Me}$

1 2
A Little Like Me 3
A Lot Like Me

4

2. I like it when the questions in math make me think.

Very Different From Me

1

A Little Different From $\mathrm{Me}$

2
A Little Like Me

3

A Little Like Me

3
A Lot Like Me

4

A Lot Like Me

4

4. If the teacher discusses something interesting I might do more math with it.

Very Different From Me

1
A Little Different From $\mathrm{Me}$

2

A Little Like Me 3

A Little Like Me

A Little Like Me 3

A Lot Like Me 4

5. I like hard, challenging math.

Very Different From Me

1
A Little Different From $\mathrm{Me}$

2
3

6. I enjoy a long, involved math problem.
A Little Different From $\mathrm{Me}$

2

A Lot Like Me 4

A Lot Like Me 4

7. I know that I will do well in math next year.

Very Different From Me

1
A Little Different From $\mathrm{Me}$

A Little Like Me 3

8. If a math problem is interesting I don't care how hard it is to solve.

Very Different From Me A Little Different From $\quad$ Me $\quad$ A Little Like Me

A Lot Like Me 1 2 3 4 
9. I try to get more answers right than my friends.

Very Different From Me A Little Different From $\mathrm{Me}$

1

2

A Little Like Me

A Lot Like Me

3

4

10. I have favorite subjects that I like to do math about.

Very Different From Me

1
A Little Different From $\mathrm{Me}$

2
A Little Like Me 3
A Lot Like Me

4

A Little Like Me 3
A Lot Like Me 4

12. I make pictures in my mind when I solve math problems.
Very Different From Me A Little Different From A Little Like Me $\mathrm{Me}$

1

2
A Lot Like Me 4

13. I don't like doing math when the problems are too difficult.

Very Different From Me

1
A Little Different From $\mathrm{Me}$

2
A Little Like Me 3
A Lot Like Me 4

14. I enjoy doing math problems with algebra.

Very Different From Me

1
A Little Different From $\mathrm{Me}$

2
A Little Like Me 3
A Lot Like Me 4

15. I am a good mathematician.

Very Different From Me

1
A Little Different From $\mathrm{Me}$

2
A Little Like Me 3
A Lot Like Me

4

16. I usually learn difficult things by doing math.

Very Different From Me A Little Different From
Me

A Little Like Me 3

A Lot Like Me 4 
17. It is very important to me to be a good mathematician.

$\begin{array}{cccc}\text { Very Different From Me } & \begin{array}{c}\text { A Little Different From } \\ \text { Me }\end{array} & \text { A Little Like Me } & \text { A Lot Like Me } \\ 1 & 2 & 3 & 4\end{array}$

18. My parents often tell me what a good job I am doing in math.

$\begin{array}{cccc}\text { Very Different From Me } & \begin{array}{c}\text { A Little Different From } \\ \text { Me }\end{array} & \text { A Little Like Me } & \text { A Lot Like Me } \\ 1 & 2 & 3 & 4\end{array}$

19. I do math to learn new information about topics that interest me.
Very Different From Me A Little Different From A Little Like Me $\mathrm{Me}$

A Little Like Me A Lot Like Me

1

2

3

4

20. If the project is interesting, I can do difficult math.

$\begin{array}{cc}\text { Very Different From Me } & \text { A Little Different From } \\ \text { Me } & \text { A Little Like Me }\end{array}$

123

3

A Lot Like Me

4

21. I learn more from doing math than most students in the class.

Very Different From Me

1
A Little Different From $\mathrm{Me}$

2
A Little Like Me 3

A Lot Like Me 4

22. I complete math problems with geometry.

Very Different From Me

1
A Little Different From $\mathrm{Me}$

2
A Little Like Me

$$
3
$$

A Little Like Me 3

A Little Like Me

3

A Lot Like Me

4

23. I do math because I have to.

Very Different From Me

1
A Little Different From $\mathrm{Me}$

2

24. I don't like math questions.

$$
\begin{gathered}
\text { Very Different From Me } \quad \begin{array}{c}
\text { A Little Different From } \\
\text { Me }
\end{array}
\end{gathered}
$$$$
1
$$$$
2
$$

A Lot Like Me

4

A Lot Like Me

4 
25. I like to do math about new things.

Very Different From Me
A Little Different From $\mathrm{Me}$

2
A Little Like Me

3
A Lot Like Me

4

26. I often do math with my brother or sister.

Very Different From Me

1
A Little Different From $\mathrm{Me}$
A Little Like Me
A Lot Like Me

4

27. In comparison to other activities I do, it is very important to me to be a good mathematician.

\section{Very Different From Me}

1
A Little Different From $\mathrm{Me}$

2
A Little Like Me

3
A Lot Like Me

4

28. I like having the teacher say I do math well.

$\begin{array}{cccc}\text { Very Different From Me } & \begin{array}{c}\text { A Little Different From } \\ \text { Me }\end{array} & \text { A Little Like Me } & \text { A Lot Like Me } \\ 1 & 2 & 3 & 4\end{array}$

29. I do math about my hobbies to learn more about them.

Very Different From Me

1
A Little Different From $\mathrm{Me}$

2
A Little Like Me 3
A Lot Like Me 4

30. I like measurement.

Very Different From Me

1
A Little Different From
Me 2
A Little Like Me 3
A Lot Like Me

4

A Lot Like Me

Very Different From Me

1
A Little Different From

2
A Little Like Me 3
4

32. Complicated math problems are no fun to complete.
Very Different From Me A Little Different From $\mathrm{Me}$

A Little Like Me 3
A Lot Like Me 4 
33. I complete a lot of data problems in math.

$\begin{array}{cccc}\text { Very Different From Me } & \begin{array}{c}\text { A Little Different From } \\ \text { Me }\end{array} & \text { A Little Like Me } & \text { A Lot Like Me } \\ 1 & 2 & 3 & 4\end{array}$

34. I do as little schoolwork as possible in math.

Very Different From Me

1
A Little Different From $\mathrm{Me}$

2
A Little Like Me
A Lot Like Me

4

A Lot Like Me 4

A Lot Like Me 4

A Lot Like Me 4

A Lot Like Me
4

A Lot Like Me 4

40. I don't like it when there are too many numbers in a math problem.

$\begin{array}{ccc}\text { Very Different From Me } & \text { A Little Different From } \\ \text { Me } & \text { A Little Like Me }\end{array}$

A Lot Like Me 1 2 3 
41. I am willing to work hard to do math better than my friends.

$\begin{array}{cccc}\text { Very Different From Me } & \begin{array}{c}\text { A Little Different From } \\ \text { Me }\end{array} & \text { A Little Like Me } & \text { A Lot Like Me } \\ 1 & 2 & 3 & 4\end{array}$

42. I sometimes do math with my parents.

Very Different From Me

1
A Little Different From $\mathrm{Me}$

2

43. I like to get compliments for my math work.
1
Very Different From Me
A Little Different From $\mathrm{Me}$
A Little Like Me 3
A Lot Like Me

4

A Little Like Me 3
A Lot Like Me 4

A Lot Like Me 4

A Lot Like Me 4

A Lot Like Me 4
A Little Like Me 3 $\begin{array}{ccc}\text { Very Different From Me } & \begin{array}{c}\text { A Little Different From } \\ \text { Me }\end{array} & \text { A Little Like Me }\end{array}$ 1 2 3
47. I am happy when someone recognizes my math work.

Very Different From Me
A Little Different From A Little Like Me

1 2 3

A Lot Like Me 4

48. I like to tell my family about what I am working on in math.

$\begin{array}{ccc}\text { Very Different From Me } & \text { A Little Different From } & \text { A Little Like Me }\end{array}$
1 2 3
A Lot Like Me 4 
49. I like being the only one who knows an answer to a math problem.

$\begin{array}{cccc}\text { Very Different From Me } & \begin{array}{c}\text { A Little Different From } \\ \text { Me }\end{array} & \text { A Little Like Me } & \text { A Lot Like Me } \\ 1 & 2 & 3 & 4\end{array}$

50. I look forward to finding out my math grade.

$\begin{array}{cccc}\text { Very Different From Me } & \begin{array}{c}\text { A Little Different From } \\ \text { Me }\end{array} & \text { A Little Like Me } & \text { A Lot Like Me } \\ 1 & 2 & 3 & 4\end{array}$

51. I always do my math work exactly as my teacher wants it.

Very Different From Me

1
A Little Different From $\mathrm{Me}$

2
A Little Like Me 3
A Lot Like Me 4

52. I like to finish my math before other students.

Very Different From Me

1
A Little Different From $\mathrm{Me}$

2
A Little Like Me 3

A Little Like Me
A Lot Like Me 4

53. My parents ask me about my math grade.
Very Different From Me
A Little Different From $\mathrm{Me}$

1
2
A Lot Like Me 4 


\section{Motivations for Math Questionnaire}

Wigfield \& Guthrie, 1997

Edited for Research

53 items

11 constructs

\section{Math Efficacy (3 items)}

$\square$ I know that I will do well in math next year.

$\square$ I am a good mathematician.

$\square \quad$ I learn more from doing math than most students in the class.

\section{Math Challenge (5 items)}

$\square \quad$ I like hard, challenging math.

$\square$ If the project is interesting, I can do difficult math.

I like it when the questions in math make me think.

$\square$ I usually learn difficult things by doing math.

$\square$ If a math problem is interesting I don't care how hard it is to solve.

\section{Math Curiosity (6 items)}

$\square$ If the teacher discusses something interesting I might do more math with it.

$\square \quad$ I have favorite subjects that I like to do math about.

$\square$ I do math to learn new information about topics that interest me.

$\square$ I do math about my hobbies to learn more about them.

$\square \quad$ I like to do math about new things.

$\square$ I enjoy doing math problems with algebra.

\section{Math Involvement (6 items)}

$\square$ I complete math problems with geometry.

$\square \quad$ I like measurement.

I make pictures in my mind when I solve math problems.

$\square \quad$ I feel like I make friends with people in good word problems.

$\square$ I complete a lot of data problems in math.

$\square$ I enjoy a long, involved math problem.

\section{Importance of Math (2 items)}

$\square \quad$ It is very important to me to be a good mathematician.

$\square$ In comparison to other activities I do, it is very important to me to be a good mathematician.

\section{Math Work Avoidance (4 items)}

$\square$ I don't like math questions.

$\square$ Complicated math problems are no fun to complete.

$\square$ I don't like doing math when the problems are too difficult.

$\square$ I don't like it when there are too many numbers in a math problem.

\section{Competition in Math (6 items)}

$\square \quad$ I try to get more answers right than my friends.

$\square \quad$ I like being the best at math.

I like to finish my math before other students.

I like being the only one who knows an answer to a math problem.

$\square$ It is important for me to see my name on a list of good mathematicians.

$\square \quad$ I am willing to work hard to do math better than my friends. 


\section{Recognition for Math (5 items)}

$\square \quad$ I like having the teacher say I do math well.

$\square$ My friends sometimes tell me I am a good mathematician.

I I like to get compliments for my math work.

$\square \quad$ I am happy when someone recognizes my math work.

$\square$ My parents often tell me what a good job I am doing in math.

Math for Grades (4 items)

$\square$ Grades are a good way to see how well you are doing in math.

$\square$ I look forward to finding out my math grade.

$\square \quad$ I do math to improve my grades.

$\square$ My parents often tell me what a good job I am doing in math.

Social Reasons for Math (7 items)

$\square \quad$ I do math often with my family.

$\square$ I often do math with my brother or sister.

$\square$ My friends and I like to trade math problems.

$\square \quad$ I sometimes do math with my parents.

$\square$ I talk to my friends about what I am working on in math.

$\square \quad$ I like to help my friends with their schoolwork in math.

$\square \quad$ I like to tell my family about what I am working on in math.

\section{Compliance (5 items)}

$\square$ I do as little schoolwork as possible in math.

$\square \quad$ I do math because I have to.

I I always do my math work exactly as my teacher wants it.

$\square$ Finishing every math assignment is very important to me.

$\square$ I always try to finish my math work on time. 